\title{
Neuroimaging and Resilience Factors - Staging of the At-risk Mental State?
}

\author{
Renata Smieskova ${ }^{1,2, *}$, Paolo Fusar-Poli ${ }^{3}$, Anita Riecher-Rössler ${ }^{1}$ and Stefan Borgwardt ${ }^{1,2,3}$
}

\author{
${ }^{1}$ Department of Psychiatry, University of Basel, 4031 Basel, Switzerland, ${ }^{2}$ Medical Image Analysis Centre, University of Basel, Swit- \\ zerland, ${ }^{3}$ King's College London, Institute of Psychiatry, Department of Psychosis Studies, De Crespigny Park, London SE5 8 AF, \\ United Kingdom
}

\begin{abstract}
Over the past decade, vulnerability- and psychosis-associated structural and functional brain abnormalities in a population at high clinical risk to develop psychosis were intensively studied. We reviewed the results from studies comparing at-risk mental state (ARMS) individuals with and without subsequent transition to psychosis. Additionally, we introduced a new concept of splitting ARMS population according to the duration of the psychosis risk syndrome and their probability to develop psychosis. Studying the ARMS individuals still vulnerable to psychosis but with lower risk to transit can disclose the possible protective - resilience factors or characteristics. Resilience, understood as ability to recover from change, can be thus applied in the early intervention for high clinical risk for psychosis individuals.
\end{abstract}

Keywords: At-risk mental state (ARMS), transition, psychosis, resilience, magnetic resonance imaging (MRI).

\section{THE PRODROMAL STAGE OF PSYCHOSIS}

The research in the prodromal stages of serious physical diseases, e.g. cardiovascular and oncological diseases, has exponentially progressed. Similarly, over the last decades early clinical detection and intervention in patients with psychoses have become widespread. Psychosis seems to be preventable or at least successfully treatable in the early stages before frank psychosis breakdown $[1,2]$. Early detection services worldwide [3-5] identify individuals, who are experiencing prodromal symptoms characterized by attenuated psychotic symptoms, or brief limited psychotic symptoms or a decline in social and/or occupational functioning. They are broadly termed as having a clinical high-risk or an 'at risk mental state' (ARMS) (for review see [6]), more recently as the 'Psychosis Risk Syndrome' [7]. Research in early and prodromal phases of the illness may provide important findings on etiology that are not confounded by medication and/or chronicity related effects.

The developing psychosis is understood as a continuum with early mild clinical signs [6, 8-10]. A high-risk state of psychosis may be a consequence of a genetic predisposition [11] and/or geneneurodevelopmental interaction [12-14] and/or other stress factors [15] leading to the increased clinical risk for psychosis. Around 15$40 \%[2,3,5,13,16]$ of these high-risk individuals go on to develop psychosis with more severe symptoms and some of them continue to a serious chronic disease. Research has attempted to identify definitive markers that distinguish those, who go on to develop psychosis from those, who do not. However, it is difficult to identify the individuals, who will later develop psychosis solely on clinical or symptomatic grounds. Therefore, we are facing the need to additionally characterize vulnerability- and resilience-associated neurobiological markers. Neuroimaging methods help to clarify the mechanisms underlying psychosis, as the same individuals can be studied before and after the onset of frank psychosis, often with only minimal confounding effects of the previous treatment.

The term 'at-risk mental state' (ARMS) has been suggested as a replacement of the term 'prodromal', to delineate a subthreshold syndrome that confers high - but not inevitable - risk for development of psychotic disorder in the near future [5]. The ARMS is defined according to the PACE (Personal Assessment and Crisis Evaluation Clinic, Melbourne) criteria and requires individuals to

*Address correspondence to this author at the Department of Psychiatry, University of Basel, c/o University Hospital Basel, Petersgraben 4, 4031 Basel, Switzerland; Tel: 004161 2657879; Fax: 004161 2654588;

E-mail: Renata.Smieskova@upkbs.ch present a) attenuated positive psychotic or b) brief limited intermittent symptoms that do not reach the threshold of frank psychosis or c) functional decline and genetic risk $[3,16,17]$. These psychopathological symptoms are often associated with negative symptoms $[3,9]$ and subtle cognitive deficits [3, 18-20]. Furthermore, neurofunctional deficits may be associated with transition to psychosis and thus can be seen as vulnerability markers for developing frank psychosis $[3,21]$.

\section{NEUROIMAGING FINDINGS IN PSYCHOSIS}

Postmortem $[22,23]$ as well as neuroimaging studies described brain structural deficits of patients suffering from psychosis [24]. The most replicated and pronounced findings are increase of ventricular volumes and reduction of total gray matter, white matter and whole brain volume [25-27]. Meta-analyses of voxel based morphometry studies in schizophrenia have shown additional regional gray matter volume (GMV) reduction in the anterior cingulate, insula, medial prefrontal and temporal cortex, in the thalamic and other subcortical regions [28-31]. In first-episode patients, hippocampal, thalamic, insular and cingulate cortex reductions are involved [32]. More extensive reductions in medial and dorsolateral prefrontal cortex and in the superior temporal gyrus have been observed in chronic schizophrenia [32]. A number of confounding factors may influence the heterogeneity across imaging findings $[33,34]$, in particular antipsychotic medication may play a prominent role [35]. However, conflicting results across studies prevent applicability of imaging methods in clinical psychiatry.Some of the brain structural abnormalities have been characterized as trait factors, known to be present in relatives of schizophrenia patients [36, 37].Other disease-related abnormalities seem to be state markers, i.e. markers of very early stages (high clinical risk for psychosis), of transition to full-blown psychosis or of chronic disease. Pantelis et al. described acceleration of gray matter reduction specifically in prefrontal region in first-episode patients, prodromal patients and high-risk individuals [12]. Not only abnormalities in the brain network, but also reduced connectivity between distinct brain regions appear to apply across all stages of schizophrenia [38].

On the other hand, several neurofunctional abnormalities have been described in patients suffering from psychosis. Executive function impairments including working memory (WM) [39-47], spatial memory and verbal fluency deficits [48-55], and reward and salience processing anomalies [56-59] are pronounced cognitive features found in schizophrenia. However, the relation of physiological and clinical variables (positive, negative symptoms) is 
complicated by the multidimensional nature of psychotic symptoms. Using specific functional paradigms, individuals suffering from schizophrenia manifested failure of some brain regions to activate to a task while other regions were over-activated [60].

\section{STRUCTURAL AND NEUROFUNCTIONAL BRAIN- IMAGING FINDINGS IN ARMS}

Over the past decade, structural magnetic resonance imaging (MRI) methods have been extensively employed to identify neuroanatomical alterations in the pre-psychotic phases. Several techniques were implemented to investigate structural differences in ARMS individuals: voxel-based morphometry for gray [61-63] and white matter [64], region-of-interest analyses of hippocampal, cingulate and pituitary areas [65-73], cortical thickness [74] and pattern matching [75, 76], and gyrification index [77]. Overall, in subjects at high-risk for psychosis with subsequent transition to psychosis, as compared to the high-risk individuals without subsequent transition, MRI studies showed volumetric reductions in frontal, insular, cingulate, lateral and middle temporal, and cerebellar regions $[13,61-63,66,71,75,76,78,79]$. These regions are similar to the regions of structural deficits found in first-episode schizophrenia [80-84] and in the relatives of schizophrenia patients $[85,86]$. The latter indicates that the volumetric reductions in these regions are not only affected in prodromal or manifest psychosis but also represent potential vulnerability markers for the illness. Recent advances in psychiatric research indicate that neurocognitive deficits are also evident in subjects with an at-risk mental state (ARMS) $[19,87-90]$ and in non-affected first-degree relatives [9196].

Functional MRI studies are based on known impaired cognitive domains in the early stages of schizophrenic psychosis. They use an 'activation paradigm', which engages the brain region/s of interest and the results reflect abnormalities in these specific cognitive domains. Some of the published fMRI and multimodal functional studies investigated neurofunctional abnormalities in ARMS [9799] and found deficits in the frontal and temporal task-related networks $[100,101]$. Several studies focused on functional deficits, while performing a working memory task [20, 97, 102, 103]. Such alterations cannot be attributed to the effects of illness or treatment and may represent markers of vulnerability to psychosis [100].

\section{RESILIENCE FACTORS AND CLINICAL STAGING OF THE ARMS}

Importantly, $90 \%$ of the ARMS individuals who made a transition to frank psychosis (ARMS-T) did this during the first two years after ascertainment [3]. After these two years, only further 3\% of all included ARMS individuals developed frank psychosis, representing a 10-fold lower risk for transition as compared to the first two years after ascertainment (36\% probability to transit) [3]. Similarly, a study by Yung confirmed that the vast majority of transitions occurred in the first two years (estimated hazard ratio 0.58) and significantly dropped over time (estimated hazard ratio 0.07) [104].

Some recent studies aiming to improve individual risk assessment showed that transition rate was declining over the past years $[105,106]$. During the first two years, the transition rate declined from $31 \%$ published in 2003 [79] to $16 \%$ published five years later in a high-risk population [107]. The reasons for this decline are not completely clear. Most probably, individuals are more readily referred to early detection clinics than 10 years ago. Those identified as "at risk" might be less severely ill and therefore have a lower risk to rapid deterioration. Furthermore, the decline might be a result of non-pharmacological interventions, such as psychosocial intervention, family support, cognitive behavioral therapy (CBT) or other unknown (possibly protective) factors. Some ARMS individuals may have better internal resources, attitudinal approaches and overall functioning as seen by non-medicated schizophrenia patients [108]. They may recover subsequently [109]. Other indi- viduals may be on the ARMS continuum for a longer period of time. The longer the subclinical psychosis persists in the general population over time, the greater the risk of transition to clinical psychosis as shown in a recently published 8-year cohort study [110].

A worldwide-accepted clinical staging model of psychotic disorders [1,2] describes stages of ongoing psychosis with its characteristics and recommended treatment. Interventions according to the model should lead to prevention or delay of progression from earlier to later stages of disorder, and they should be chosen on a careful risk/benefit analysis $[2,111]$. This approach can enable us to allocate each individual according to his/her deficits or abnormalities and to provide accurate intervention.

We postulate that those ARMS individuals, who are more vulnerable to transition and therefore have a higher probability for transition to psychosis, have less resilience factors and vice versa. Therefore, we suggest splitting the individuals with an ARMS according to the duration of their ARMS as well as according to their clinical outcome (Fig. 1). The first criterion focuses on the time span of risk: the short-term ARMS (ARMS-ST) group consists of ARMS individuals in a period shorter than two years after ascertainment; individuals, who are in ARMS continuum longer than two years belong to the second group (long-term ARMS, ARMSLT). ARMS-LT individuals might represent a group with a vulnerability to psychosis but a relatively moderate or low transition probability [3]. All of the ARMS (ARMS-ST and ARMS-LT) still have to meet the PACE criteria and have not recovered in the meantime. According to the clinical outcomes ARMS individuals with subsequent transition to psychosis belong to the ARMS-T group. There were published several studies comparing ARMS-T and ARMS-NT (ARMS with no transition to psychosis) individuals (for review see [30]). ARMS-ST subjects are vulnerable to psychosis and we expect that around $30 \%$ out of them will transit (ARMS-T) in next two years, leaving still $70 \%$ of ARMS without transition to psychosis (ARMS-NT). The latter are of high clinical and research relevance and may be called ARMS-LT. We suggest following them longitudinally with the aim to investigate the course of their symptomatology and functioning as well as resilience factors protecting them from developing frank psychosis.

Thus the two ARMS subgroups (ARMS-ST and ARMS-LT) represent vulnerability groups to psychosis with different probabilities of later transition to psychosis. The ARMS-LT group might either recover, or develop psychosis or other disease, or remain on the risk continuum to develop psychosis. Still, according to the published data the ARMS-LT group has lower probability to develop subsequent psychosis than ARMS-ST. This interesting group could help us to define resilience factors in the at-risk mental state.

The spectrum of subsequent diagnoses and possible comorbid symptoms remains broad and worth to be studied further. Longitudinally followed-up groups of ARMS without transition give us an opportunity to better understand the trajectory of the disease process, when the vulnerability to transit is not subsequently followed by transition and when these ARMS individuals stay somehow protected. We are aware of inhomogeneity of this group and expect to detect broad spectrum of diagnoses or comorbid symptoms in a future. But probably, we can learn from these subjects, how to cope with their higher vulnerability to psychosis and still stay without transition.

\section{NEUROIMAGING AND STAGING OF THE RISK FOR PSYCHOSIS}

As shown in our recently published meta-analysis of neuroimaging predictors [30], there are known structural and neurofunctional deficits in ARMS individuals with subsequent transition (ARMS-T) as compared to the ARMS individuals without transition (ARMS-NT; see Table 1 summarizing data published in [30]). 


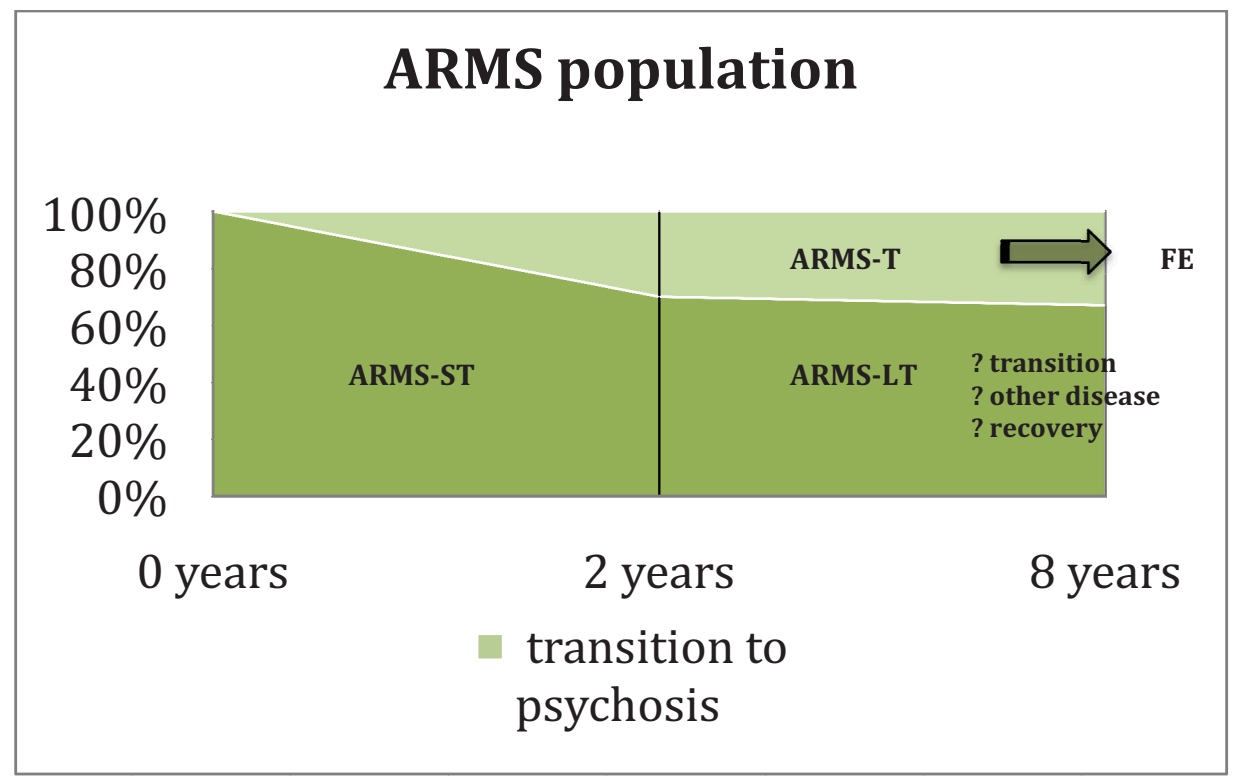

Fig. (1). ARMS population vulnerable to psychosis with descending transition probability in a time course of their at-risk state.

ARMS individuals can be divided according to the duration of their at-risk mental state into ARMS-ST (ARMS short-term) and ARMS-LT (ARMS long-term) individuals. ARMS individuals with subsequent transition to psychosis (ARMS-T) continue to first episode of psychosis (FE). ARMS-LT can be followed-up clinically and investigated for their vulnerability- and resilience-associated factors.

Later development of psychosis was associated with less GMV in the right insula, inferior frontal, and superior temporal gyrus [13]. Multimodal imaging analysis of structural and functional MRI during working memory showed association between BOLD response and gray matter in the right insula and middle temporal gyrus in all ARMS individuals [112]. ARMS-ST group had deficits similar to the ARMS-T group as showed our study comparing volumetric data of ARMS-ST and ARMS-LT groups [113]. Even more, these insular volumetric abnormalities correlated with clinical symptoms of psychosis [113]. The structural abnormalities in insular region have been described in individuals with impaired insight to the disease [114]. Positive relationship to the recovery and awareness of their abnormal experiences can be associated with increase in insular volume [115].
ARMS-LT with vulnerability to psychosis but lower transition probability might help us to find resilience-associated changes in their brain structure and function. We argue that ARMS-ST and ARMS-LT subgroups may contribute to the existing clinical staging model of psychosis.

\section{CONCLUSIONS}

Neuroimaging methods might in future contribute to the prediction of the probability for transition to psychosis and regarding the time course of illness. To be able to predict transition to psychosis as exactly as possible we should combine multimodal imaging approach with clinical symptoms and neurocognitive measures. In future, by improving the understanding of emerging psychosis, we may be able to selectively treat those patients with the highest risk

Table 1. Meta-analysis of volumetric and functional differences between ARMS-T and ARMS-NT (Modified from [30])

\begin{tabular}{|c|c|c|c|c|c|c|}
\hline \multirow{3}{*}{$\begin{array}{l}\text { ARMS-ST vs. ARMS-LT / } \\
\text { Region }\end{array}$} & \multicolumn{6}{|c|}{ Cohen's d (number of studies)* } \\
\hline & \multicolumn{3}{|c|}{ Volumetric Abnormalities } & \multicolumn{3}{|c|}{ Functional Abnormalities } \\
\hline & Increased GMV & Decreased & No Change & $\begin{array}{l}\text { Decreased } \\
\text { BOLD }\end{array}$ & NAA/Cho & Decreased 5HT BP \\
\hline Temporal cortex & $0.1-0.8(4)$ & $0.3(7)$ & (2) & - & Increased $1.0(1)$ & - \\
\hline Cingulate cortex & - & $0.4-0.9(4)$ & $(2)$ & (1) & Decreased (1) & - \\
\hline Prefrontal cortex & $0.5(1)$ & $0.1-0.9(10)$ & - & $0.6(1)$ & - & $1.5(1)$ \\
\hline Cerebellum & - & (3) & - & - & - & - \\
\hline Occipital lobe & - & - & - & (1) & - & - \\
\hline
\end{tabular}

* Numbers belonging to the affected brain region characterize range of effect size calculated as Cohen's $\mathrm{d}$ with the number of included studies in parentheses. When there is no Cohen's d, the effect size was not possible to calculate.

Abbreviations:

ARMS-NT - at-risk mental state without transition, ARMS-T - at-risk mental state with transition, BOLD - bold oxygen level dependency (fMRI parameter), $\mathrm{NAA} / \mathrm{Cho}$ - $\mathrm{N}$-acetylaspartate/cholin containing compounds (MRS parameter), 5HT BP - serotonin binding potential (PET parameter) 
for psychosis. The treatment will be thus more efficient, selectively targeted and can integrate resilience-based non-pharmacological interventions to clinical psychiatry.

\section{ABBREVIATIONS}

$\begin{array}{ll}\text { ARMS } & =\text { At-risk mental state } \\ \text { ARMS-LT } & =\text { At-risk mental state long term } \\ \text { ARMS-NT } & =\text { At-risk mental state without transition } \\ \text { ARMS-ST } & =\text { At-risk mental state short term } \\ \text { ARMS-T } & =\text { At-risk mental state with transition } \\ \text { CBT } & =\text { Cognitive behavioral therapy } \\ \text { fMRI } & =\text { Functional magnetic resonance imaging } \\ \text { GMV } & =\text { Gray matter volume } \\ \text { MRS } & =\text { Magnetic resonance spectroscopy } \\ \text { PACE } & =\text { Personal Assessment and Crisis Evaluation } \\ \text { PET } & =\text { Positron emission tomography } \\ \text { sMRI } & =\text { Structural magnetic resonance imaging } \\ \text { WM } & =\text { Working memory }\end{array}$

\section{REFERENCES}

[1] McGorry PD, Killackey E, Yung AR. Early intervention in psychotic disorders: detection and treatment of the first episode and the critical early stages. Med J Aust 2007; 187: S8-10.

[2] McGorry PD, Nelson B, Amminger GP, et al. Intervention in individuals at ultra-high risk for psychosis: a review and future directions. J Clin Psychiatry 2009; 70: 1206-12.

[3] Riecher-Rossler A, Pflueger MO, Aston J, et al. Efficacy of using cognitive status in predicting psychosis: a 7-year follow-up. Biol Psychiatry 2009; 66: 1023-30.

[4] Mechelli R-RA, Meisenzahl EM, Tognin S, et al. Neuroanatomical abnormalities that predate the onset of psychosis: a multi-centre study. Archives of General Psychiatry 2010.

[5] Yung AR, Phillips LJ, McGorry PD, et al. Prediction of psychosis. A step towards indicated prevention of schizophrenia. $\mathrm{Br} \mathrm{J}$ Psychiatry Suppl 1998; 172: 14-20.

[6] Riecher-Rössler A, Gschwandtner U, Borgwardt S, Aston J, Pflüger M, Rössler W. Early detection and treatment of schizophrenia: how early? Acta Psychiatr Scand Suppl 2006: 7380.

[7] Woods SW, Carlson JP, McGlashan TH. DSM-5 and the 'Psychosis Risk Syndrome': The DSM-5 proposal is better than DSM-IV. Psychosis 2010; 2: 187-90.

[8] Yung AR, Phillips LJ, McGorry PD, et al. Prediction of psychosis. A step towards indicated prevention of schizophrenia. Br J Psychiatry Suppl 1998; 172: 14-20.

[9] Lencz T, Smith CW, Auther A, Correll CU, Cornblatt B. Nonspecific and attenuated negative symptoms in patients at clinical high-risk for schizophrenia. Schizophr Res 2004; 68: 3748.

[10] Häfner H, Riecher A, Maurer K, et al. Sex differences in schizophrenic diseases. Fortschr Neurol Psychiatr 1991; 59: 34360.

[11] Lawrie SM, McIntosh AM, Hall J, Owens DG, Johnstone EC. Brain structure and function changes during the development of schizophrenia: the evidence from studies of subjects at increased genetic risk. Schizophr Bull 2008; 34: 330-40.

[12] Pantelis C, Yucel M, Wood SJ, et al. Structural brain imaging evidence for multiple pathological processes at different stages of brain development in schizophrenia. Schizophr Bull 2005; 31: 67296.

[13] Borgwardt SJ, Riecher-Rossler A, Dazzan P, et al. Regional gray matter volume abnormalities in the at risk mental state. Biol Psychiatry 2007; 61: 1148-56.

[14] DeLisi LE. The concept of progressive brain change in schizophrenia: implications for understanding schizophrenia. Schizophr Bull 2008; 34: 312-21.
[15] van Os J, Rutten BP, Poulton R. Gene-environment interactions in schizophrenia: review of epidemiological findings and future directions. Schizophr Bull 2008; 34: 1066-82.

[16] Riecher-Rossler A, Gschwandtner U, Aston J, et al. The Basel early-detection-of-psychosis (FEPSY)-study--design and preliminary results. Acta Psychiatr Scand 2007; 115: 114-25.

[17] Yung AR, Phillips LJ, Yuen HP, McGorry PD. Risk factors for psychosis in an ultra high-risk group: psychopathology and clinical features. Schizophr Res 2004; 67: 131-42.

[18] Brewer WJ, Wood SJ, Phillips LJ, et al. Generalized and specific cognitive performance in clinical high-risk cohorts: a review highlighting potential vulnerability markers for psychosis. Schizophr Bull 2006; 32: 538-55.

[19] Simon AE, Cattapan-Ludewig K, Zmilacher S, et al. Cognitive functioning in the schizophrenia prodrome. Schizophr Bull 2007; 33: 761-71.

[20] Broome MR, Fusar-Poli P, Matthiasson P, et al. Neural correlates of visuospatial working memory in the 'at-risk mental state'. Psychol Med 2010; 40: 1987-99.

[21] Morey RA, Inan S, Mitchell TV, Perkins DO, Lieberman JA, Belger A. Imaging frontostriatal function in ultra-high-risk, early, and chronic schizophrenia during executive processing. Arch Gen Psychiatry 2005; 62: 254-62.

[22] Pakkenberg B. Post-mortem study of chronic schizophrenic brains. Br J Psychiatry 1987; 151: 744-52.

[23] Dorph-Petersen KA, Pierri JN, Wu Q, Sampson AR, Lewis DA. Primary visual cortex volume and total neuron number are reduced in schizophrenia. J Comp Neurol 2007; 501: 290-301.

[24] Wright IC, Rabe-Hesketh S, Woodruff PW, David AS, Murray RM, Bullmore ET. Meta-analysis of regional brain volumes in schizophrenia. Am J Psychiatry 2000; 157: 16-25.

[25] Meyer-Lindenberg A. From maps to mechanisms through neuroimaging of schizophrenia. Nature 2010; 468: 194-202.

[26] McGuire P, Howes OD, Stone J, Fusar-Poli P. Functional neuroimaging in schizophrenia: diagnosis and drug discovery. Trends Pharmacol Sci 2008; 29: 91-8.

[27] Fusar-Poli P, Allen P, McGuire P. Neuroimaging studies of the early stages of psychosis: a critical review. Eur Psychiatry 2008; 23: $237-44$.

[28] Glahn DC, Laird AR, Ellison-Wright I, et al. Meta-analysis of gray matter anomalies in schizophrenia: application of anatomic likelihood estimation and network analysis. Biol Psychiatry 2008; 64: 774-81.

[29] Fornito A, Yücel M, Patti J, Wood SJ, Pantelis C. Mapping grey matter reductions in schizophrenia: an anatomical likelihood estimation analysis of voxel-based morphometry studies. Schizophr Res 2009; 108: 104-13.

[30] Smieskova R, Fusar-Poli P, Allen P, et al. Neuroimaging predictors of transition to psychosis--a systematic review and meta-analysis. Neurosci Biobehav Rev 2010; 34: 1207-22.

[31] Fusar-Poli P, Borgwardt S, Crescini A, et al. Neuroanatomy of vulnerability to psychosis: a voxel-based meta-analysis. Neurosci Biobehav Rev 2011; 35: 1175-85.

[32] Ellison-Wright I, Glahn DC, Laird AR, Thelen SM, Bullmore E. The anatomy of first-episode and chronic schizophrenia: an anatomical likelihood estimation meta-analysis. Am J Psychiatry 2008; 165: 1015-23.

[33] Fusar-Poli P, Bhattacharyya S, Allen P, et al. Effect of image analysis software on neurofunctional activation during processing of emotional human faces. J Clin Neurosci 2010; 17: 311-4.

[34] Fusar-Poli P, Broome MR. Conceptual issues in psychiatric neuroimaging. Curr Opin Psychiatry 2006; 19: 608-12.

[35] Smieskova R, Fusar-Poli P, Allen P, et al. The effects of antipsychotics on the brain: what have we learnt from structural imaging of schizophrenia?--a systematic review. Curr Pharm Des 2009; 15: 2535-49.

[36] Boos HB, Aleman A, Cahn W, Hulshoff Pol H, Kahn RS. Brain volumes in relatives of patients with schizophrenia: a metaanalysis. Arch Gen Psychiatry 2007; 64: 297-304.

[37] Boos HB, Cahn W, van Haren NE, et al. Focal And Global Brain Measurements in Siblings of Patients With Schizophrenia. Schizophr Bull 2011.

[38] Pettersson-Yeo W, Allen P, Benetti S, McGuire P, Mechelli A. Dysconnectivity in schizophrenia: where are we now? Neurosci Biobehav Rev 2011; 35: 1110-24. 
[39] Callicott JH, Egan MF, Mattay VS, et al. Abnormal fMRI response of the dorsolateral prefrontal cortex in cognitively intact siblings of patients with schizophrenia. Am J Psychiatry 2003; 160: 709-19.

[40] Cannon TD, Glahn DC, Kim J, et al. Dorsolateral prefrontal cortex activity during maintenance and manipulation of information in working memory in patients with schizophrenia. Arch Gen Psychiatry 2005; 62: 1071-80.

[41] Forbes NF, Carrick LA, McIntosh AM, Lawrie SM. Working memory in schizophrenia: a meta-analysis. Psychol Med 2009; 39: 889-905.

[42] Glahn DC, Ragland JD, Abramoff A, et al. Beyond hypofrontality: a quantitative meta-analysis of functional neuroimaging studies of working memory in schizophrenia. Hum Brain Mapp 2005; 25: 609.

[43] Jansma JM, Ramsey NF, van der Wee NJ, Kahn RS. Working memory capacity in schizophrenia: a parametric fMRI study. Schizophr Res 2004; 68: 159-71.

[44] Johnson MR, Morris NA, Astur RS, et al. A functional magnetic resonance imaging study of working memory abnormalities in schizophrenia. Biol Psychiatry 2006; 60: 11-21.

[45] Manoach DS, Gollub RL, Benson ES, et al. Schizophrenic subjects show aberrant fMRI activation of dorsolateral prefrontal cortex and basal ganglia during working memory performance. Biol Psychiatry 2000; 48: 99-109.

[46] Menon V, Anagnoson RT, Mathalon DH, Glover GH, Pfefferbaum A. Functional neuroanatomy of auditory working memory in schizophrenia: relation to positive and negative symptoms. Neuroimage 2001; 13: 433-46.

[47] Schneider F, Habel U, Reske M, et al. Neural correlates of working memory dysfunction in first-episode schizophrenia patients: an fMRI multi-center study. Schizophr Res 2007; 89: 198-210.

[48] Ozgurdal S, Littmann E, Hauser $\mathrm{M}$, et al. Neurocognitive performances in participants of at-risk mental state for schizophrenia and in first-episode patients. J Clin Exp Neuropsychol 2009; 31: 392-401.

[49] Hambrecht M, Lammertink M, Klosterkotter J, Matuschek E, Pukrop R. Subjective and objective neuropsychological abnormalities in a psychosis prodrome clinic. Br J Psychiatry Suppl 2002; 43: s30-7.

[50] Frommann I, Pukrop R, Brinkmeyer J, et al. Neuropsychological Profiles in Different At-Risk States of Psychosis: Executive Control Impairment in the Early--and Additional Memory Dysfunction in the Late--Prodromal State. Schizophr Bull 2010.

[51] Seidman LJ, Giuliano AJ, Meyer EC, et al. Neuropsychology of the prodrome to psychosis in the NAPLS consortium: relationship to family history and conversion to psychosis. Arch Gen Psychiatry 2010; 67: 578-88.

[52] Becker HE, Nieman DH, Dingemans PM, van de Fliert JR, De Haan L, Linszen DH. Verbal fluency as a possible predictor for psychosis. Eur Psychiatry 2010; 25: 105-10.

[53] Korver N, Nieman DH, Becker HE, et al. Symptomatology and neuropsychological functioning in cannabis using subjects at ultrahigh risk for developing psychosis and healthy controls. Aust N Z J Psychiatry 2010; 44: 230-6.

[54] Pauly K, Seiferth NY, Kellermann T, et al. The interaction of working memory and emotion in persons clinically at risk for psychosis: an fMRI pilot study. Schizophr Res 2010; 120: 167-76.

[55] Fusar-Poli P, Broome MR, Matthiasson P, et al. Spatial working memory in individuals at high risk for psychosis: longitudinal fMRI study. Schizophr Res 2010; 123: 45-52.

[56] Juckel G, Schlagenhauf F, Koslowski M, et al. Dysfunction of ventral striatal reward prediction in schizophrenia. Neuroimage 2006; 29: 409-16.

[57] Murray GK, Corlett PR, Clark L, et al. Substantia nigra/ventral tegmental reward prediction error disruption in psychosis. Mol Psychiatry 2008; 13: 239, 267-76.

[58] Roiser JP, Stephan KE, den Ouden HE, Barnes TR, Friston KJ, Joyce EM. Do patients with schizophrenia exhibit aberrant salience? Psychol Med 2009; 39: 199-209.

[59] Simon JJ, Biller A, Walther S, et al. Neural correlates of reward processing in schizophrenia--relationship to apathy and depression. Schizophr Res 2010; 118: 154-61.

[60] Gur RE. Neuropsychiatric aspects of schizophrenia. CNS Neurosci Ther 2011; 17: 45-51.
[61] Borgwardt SJ, McGuire PK, Aston J, et al. Structural brain abnormalities in individuals with an at-risk mental state who later develop psychosis. Br J Psychiatry Suppl 2007; 51: s69-75.

[62] Koutsouleris N, Schmitt GJ, Gaser C, et al. Neuroanatomical correlates of different vulnerability states for psychosis and their clinical outcomes. Br J Psychiatry 2009; 195: 218-26.

[63] Pantelis C, Yucel M, Wood SJ, McGorry PD, Velakoulis D. Early and late neurodevelopmental disturbances in schizophrenia and their functional consequences. Aust N Z J Psychiatry 2003; 37: 399-406.

[64] Walterfang M, McGuire PK, Yung AR, et al. White matter volume changes in people who develop psychosis. Br J Psychiatry 2008; 193: 210-5.

[65] Phillips LJ, Velakoulis D, Pantelis C, et al. Non-reduction in hippocampal volume is associated with higher risk of psychosis. Schizophr Res 2002; 58: 145-58.

[66] Takahashi T, Wood SJ, Yung AR, et al. Insular cortex gray matter changes in individuals at ultra-high-risk of developing psychosis. Schizophr Res 2009; 111: 94-102.

[67] Thompson KN, Phillips LJ, Komesaroff P, et al. Stress and HPAaxis functioning in young people at ultra high risk for psychosis. J Psychiatr Res 2007; 41: 561-9.

[68] Yucel M, Wood SJ, Phillips LJ, et al. Morphology of the anterior cingulate cortex in young men at ultra-high risk of developing a psychotic illness. Br J Psychiatry 2003; 182: 518-24.

[69] Velakoulis D, Wood SJ, Wong MT, et al. Hippocampal and amygdala volumes according to psychosis stage and diagnosis: a magnetic resonance imaging study of chronic schizophrenia, firstepisode psychosis, and ultra-high-risk individuals. Arch Gen Psychiatry 2006; 63: 139-49.

[70] Wood SJ, Yucel M, Velakoulis D, et al. Hippocampal and anterior cingulate morphology in subjects at ultra-high-risk for psychosis: the role of family history of psychotic illness. Schizophr Res 2005; 75: 295-301.

[71] Fornito A, Yung AR, Wood SJ, et al. Anatomic abnormalities of the anterior cingulate cortex before psychosis onset: an MRI study of ultra-high-risk individuals. Biol Psychiatry 2008; 64: 758-65.

[72] Buschlen J, Berger GE, Borgwardt SJ, et al. Pituitary volume increase during emerging psychosis. Schizophr Res 2011; 125: 418.

[73] Buehlmann E, Berger GE, Aston J, et al. Hippocampus abnormalities in at risk mental states for psychosis? A crosssectional high resolution region of interest magnetic resonance imaging study. J Psychiatr Res 2010; 44: 447-53.

[74] Haller S, Borgwardt SJ, Schindler C, Aston J, Radue EW, RiecherRossler A. Can cortical thickness asymmetry analysis contribute to detection of at-risk mental state and first-episode psychosis? A pilot study. Radiology 2009; 250: 212-21.

[75] Takahashi T, Wood SJ, Yung AR, et al. Progressive gray matter reduction of the superior temporal gyrus during transition to psychosis. Arch Gen Psychiatry 2009; 66: 366-76.

[76] Sun D, Phillips L, Velakoulis D, et al. Progressive brain structural changes mapped as psychosis develops in 'at risk' individuals. Schizophr Res 2009; 108: 85-92.

[77] Harris JM, Moorhead TW, Miller P, et al. Increased prefrontal gyrification in a large high-risk cohort characterizes those who develop schizophrenia and reflects abnormal prefrontal development. Biol Psychiatry 2007; 62: 722-9.

[78] Borgwardt SJ, McGuire PK, Aston J, et al. Reductions in frontal, temporal and parietal volume associated with the onset of psychosis. Schizophr Res 2008; 106: 108-14.

[79] Pantelis C, Velakoulis D, McGorry PD, et al. Neuroanatomical abnormalities before and after onset of psychosis: a cross-sectional and longitudinal MRI comparison. Lancet 2003; 361: 281-8.

[80] Lieberman J, Chakos M, Wu H, et al. Longitudinal study of brain morphology in first episode schizophrenia. Biol Psychiatry 2001; 49: 487-99.

[81] Kasai K, Shenton ME, Salisbury DF, et al. Progressive decrease of left superior temporal gyrus gray matter volume in patients with first-episode schizophrenia. Am J Psychiatry 2003; 160: 156-64.

[82] Steen RG, Mull C, McClure R, Hamer RM, Lieberman JA. Brain volume in first-episode schizophrenia: systematic review and metaanalysis of magnetic resonance imaging studies. Br J Psychiatry 2006; 188: 510-8. 
[83] Vita A, De Peri L, Silenzi C, Dieci M. Brain morphology in firstepisode schizophrenia: a meta-analysis of quantitative magnetic resonance imaging studies. Schizophr Res 2006; 82: 75-88.

[84] Witthaus H, Brune M, Kaufmann C, et al. White matter abnormalities in subjects at ultra high-risk for schizophrenia and first-episode schizophrenic patients. Schizophr Res 2008; 102: 1419.

[85] Goghari VM, Rehm K, Carter CS, MacDonald AW, 3rd. Regionally specific cortical thinning and gray matter abnormalities in the healthy relatives of schizophrenia patients. Cereb Cortex 2007; 17: 415-24.

[86] Borgwardt SJ, Picchioni MM, Ettinger U, Toulopoulou T, Murray $\mathrm{R}$, McGuire PK. Regional gray matter volume in monozygotic twins concordant and discordant for schizophrenia. Biol Psychiatry 2010; 67: 956-64.

[87] Marjoram D, Job DE, Whalley HC, et al. A visual joke fMRI investigation into Theory of Mind and enhanced risk of schizophrenia. Neuroimage 2006; 31: 1850-8.

[88] Eastvold AD, Heaton RK, Cadenhead KS. Neurocognitive deficits in the (putative) prodrome and first episode of psychosis. Schizophr Res 2007; 93: 266-77.

[89] Pflueger MO, Gschwandtner U, Stieglitz RD, Riecher-Rossler A. Neuropsychological deficits in individuals with an at risk mental state for psychosis - working memory as a potential trait marker. Schizophr Res 2007; 97: 14-24.

[90] Smith CW, Park S, Cornblatt B. Spatial working memory deficits in adolescents at clinical high risk for schizophrenia. Schizophr Res 2006; 81: 211-5

[91] MacDonald AW, 3rd, Thermenos HW, Barch DM, Seidman LJ. Imaging genetic liability to schizophrenia: systematic review of FMRI studies of patients' nonpsychotic relatives. Schizophr Bull 2009; 35: 1142-62.

[92] Karch S, Leicht G, Giegling I, et al. Inefficient neural activity in patients with schizophrenia and nonpsychotic relatives of schizophrenic patients: evidence from a working memory task. J Psychiatr Res 2009; 43: 1185-94.

[93] Meda SA, Bhattarai M, Morris NA, et al. An fMRI study of working memory in first-degree unaffected relatives of schizophrenia patients. Schizophr Res 2008; 104: 85-95.

[94] Karlsgodt KH, Glahn DC, van Erp TG, et al. The relationship between performance and fMRI signal during working memory in patients with schizophrenia, unaffected co-twins, and control subjects. Schizophr Res 2007; 89: 191-7.

[95] Spence SA, Liddle PF, Stefan MD, et al. Functional anatomy of verbal fluency in people with schizophrenia and those at genetic risk. Focal dysfunction and distributed disconnectivity reappraised. Br J Psychiatry 2000; 176: 52-60.

[96] Lee J, Cohen MS, Engel SA, et al. Regional brain activity during early visual perception in unaffected siblings of schizophrenia patients. Biol Psychiatry 2010; 68: 78-85.

[97] Fusar-Poli P, Howes OD, Allen P, et al. Abnormal frontostriatal interactions in people with prodromal signs of psychosis: a multimodal imaging study. Arch Gen Psychiatry 2010; 67: 683-91.

[98] Fusar-Poli P, Howes OD, Allen P, et al. Abnormal prefrontal activation directly related to pre-synaptic striatal dopamine dysfunction in people at clinical high risk for psychosis. Mol Psychiatry 2011; 16: 67-75.
[99] Fusar-Poli P, Stone JM, Broome MR, et al. Thalamic Glutamate Levels as a Predictor of Cortical Response During Executive Functioning in Subjects at High Risk for Psychosis. Arch Gen Psychiatry 2011.

[100] Fusar-Poli P, Perez J, Broome M, et al. Neurofunctional correlates of vulnerability to psychosis: a systematic review and metaanalysis. Neurosci Biobehav Rev 2007; 31: 465-84.

[101] Allen P, Stephan KE, Mechelli A, et al. Cingulate activity and fronto-temporal connectivity in people with prodromal signs of psychosis. Neuroimage 2010; 49: 947-55.

[102] Fusar-Poli P, Broome MR, Woolley JB, et al. Altered brain function directly related to structural abnormalities in people at ultra high risk of psychosis: Longitudinal VBM-fMRI study. J Psychiatr Res 2010.

[103] Broome MR, Matthiasson P, Fusar-Poli P, et al. Neural correlates of executive function and working memory in the 'at-risk mental state'. Br J Psychiatry 2009; 194: 25-33.

[104] Yung AR, Yuen HP, Berger G, et al. Declining transition rate in ultra high risk (prodromal) services: dilution or reduction of risk? Schizophr Bull 2007; 33: 673-81.

[105] Haroun N, Dunn L, Haroun A, Cadenhead KS. Risk and protection in prodromal schizophrenia: ethical implications for clinical practice and future research. Schizophr Bull 2006; 32: 166-78.

[106] Ruhrmann S, Schultze-Lutter F, Salokangas RK, et al. Prediction of psychosis in adolescents and young adults at high risk: results from the prospective European prediction of psychosis study. Arch Gen Psychiatry 2010; 67: 241-51.

[107] Yung AR, Nelson B, Stanford C, et al. Validation of "prodromal" criteria to detect individuals at ultra high risk of psychosis: 2 year follow-up. Schizophr Res 2008; 105: 10-7.

[108] Harrow M, Jobe TH. Factors involved in outcome and recovery in schizophrenia patients not on antipsychotic medications: a 15-year multifollow-up study. J Nerv Ment Dis 2007; 195: 406-14.

[109] Simon AE, Umbricht D. High remission rates from an initial ultrahigh risk state for psychosis. Schizophr Res 2010; 116: 168-72.

[110] Dominguez MD, Wichers M, Lieb R, Wittchen HU, van Os J. Evidence that onset of clinical psychosis is an outcome of progressively more persistent subclinical psychotic experiences: an 8-year cohort study. Schizophr Bull 2011; 37: 84-93.

[111] McGorry PD, Hickie IB, Yung AR, Pantelis C, Jackson HJ. Clinical staging of psychiatric disorders: a heuristic framework for choosing earlier, safer and more effective interventions. Aust N Z J Psychiatry 2006; 40: 616-22.

[112] Smieskova R, Allen P, Simon A, et al. Different duration of at-risk mental state associated with neurofunctional abnormalities-A multimodal imaging study Hum Brain Mapp 2011; Sep 16. [Epub ahead of print] available http://onlinelibrary.wiley.com/doi/ 10.1002/hbm.21360/pdf (accessed 2011 Oct. 26).

[113] Smieskova R, Fusar-Poli P, Aston J, et al. Insular volume abnormalities associated with different transition probabilities to psychosis. Psychol Med 2011; in press.

[114] Palaniyappan L, Mallikarjun P, Joseph V, Liddle PF. Appreciating symptoms and deficits in schizophrenia: Right posterior insula and poor insight. Prog Neuropsychopharmacol Biol Psychiatry 2010.

[115] Lappin JM, Morgan KD, Valmaggia LR, et al. Insight in individuals with an At Risk Mental State. Schizophr Res 2007; 90: $238-44$. 